\title{
Investigation of Downstream Signals of the Soybean Autoregulation of Nodulation Receptor Kinase GmNARK
}

\author{
Mark Kinkema and Peter M. Gresshoff \\ Australian Research Council Centre of Excellence for Integrative Legume Research, The University of Queensland, \\ St. Lucia, QLD 4072, Australia
}

Submitted 14 April 2008. Accepted 16 June 2008.

\begin{abstract}
The Glycine max nodule autoregulation receptor kinase (GmNARK) plays a central role in the systemic signal transduction pathway controlling nodulation in soybean. We used transcriptional profiling to identify potential downstream signals of this receptor kinase. These studies revealed that GmNARK-mediated signaling controls the expression of genes involved in the jasmonic acid (JA) pathway. Genes encoding the key enzymes controlling JA biosynthesis as well as JA-response genes were regulated systemically but not locally by root inoculation with Bradyrhizobium japonicum. This systemic regulation was abolished in Gmnark mutant plants, indicating that their expression was specifically controlled by signaling events associated with this receptor kinase. Foliar application of a JA biosynthesis inhibitor significantly reduced nodulation specifically in supernodulating mutant plants. These results indicate that the receptor-mediated regulation of JA signaling plays an important role in the AON signal transduction pathway. A second class of genes was identified that were controlled by GmNARK in a rhizobia-independent manner. These candidates provide insight on additional, nonsymbiotic signaling pathways that are likely regulated by GmNARK, such as those involved in root growth and defense. The discovery of downstream components of the GmNARK receptor kinase advances our understanding of the systemic control of nodule development and its association with other signaling networks.
\end{abstract}

Additional keyword: microarray.

The symbiotic interaction between rhizobia and legume roots results in the formation of a novel organ, the nodule, that allows the plant to utilize atmospheric nitrogen for growth and development. This unique symbiosis makes legumes extremely beneficial in sustainable agriculture as a biological nitrogen fertilizer (Graham and Vance 2003). In addition, root nodule formation is

Current address for M. Kinkema: Syngenta Centre for Sugarcane Biofuel Development, Queensland University of Technology, Brisbane, QLD 4001, Australia.

Corresponding author: P. M. Gresshoff; E-mail: p.gresshoff@uq.edu.au; Fax +61 73365 3556; Telephone: +61 733653550 .

Nucleotide sequence data for Gma.9069 and Gma.736 are available in the GenBank database under accession numbers EU399509 and EU399510, respectively.

* The $\boldsymbol{e}$-Xtra logo stands for "electronic extra" and indicates that two supplemental figures and three supplemental tables are available online. interesting from a developmental perspective, because this symbiotic association involves a complex network of molecular and cellular events between the plant and microbe.

In contrast to our knowledge on nodule development (Kinkema et al. 2006; Stacey et al. 2006), relatively little is known about the molecular events involved in the regulation of nodulation. Legumes regulate nodule formation to balance the benefits of symbiotic nitrogen fixation with overall growth and development. The major pathway controlling nodulation is known as autoregulation of nodulation $(\mathrm{AON})$, which involves long-distance signaling between the root and shoot whereby early nodulation events act to inhibit subsequent nodule development (Bauer 1981; Kosslak and Bohlool 1984; CaetanoAnollés and Gresshoff 1991). Most AON mutants are characterized by a supernodulation phenotype as well as nitrate-tolerant nodulation (Carroll et al. 1985a and b; Duc and Messager 1989; Oka-Kira et al. 2005; Park and Buttery 1988; Schnabel et al. 2005; Wopereis et al. 2000). Cloning of one of the genes responsible for a supernodulating phenotype in soybean (GmNARK, Glycine max nodule autoregulation receptor kinase; Searle et al. 2003), Lotus japonicus (HARl, hypernodulation and aberrant root; Krusell et al. 2002; Nishimura et al. 2002), pea (SYM29, symbiosis; Krusell et al. 2002), and Medicago truncatula (SUNN, super numeric nodules; Schnabel et al. 2005) has revealed that a putative transmembrane, leucine-rich repeat (LRR) receptor kinase is a key regulator of the AON signaling pathway. Although transcripts for GmNARK, HARl, and SUNN are abundant in both the root and shoot (Krusell et al. 2002; Nishimura et al. 2002; Nontachaiyapoom et al. 2007; Schnabel et al. 2005; Yamamoto et al. 2000), grafting experiments have shown that the nodulation phenotype is controlled by the shoot (Delves et al. 1986; Jiang and Gresshoff 2002; Krusell et al. 2002; Nishimura et al. 2002). Based on these data, it has been proposed that AON involves the production of a rhizobia-induced signal from the root that activates the LRR receptor kinase in the shoot (Caetano-Anollés and Gresshoff 1991; Gresshoff and Delves 1986). "Activation" of this receptor kinase is thought to control the production of a shoot-derived inhibitor (SDI) that regulates nodule number in the root. Currently, the nature of the root and shoot signals is not known. In addition, downstream components involved in the receptor-mediated AON signaling have not been identified.

Mutations in the AON LRR receptor kinases have also been associated with changes in root development (Day et al. 1986; Schnabel et al. 2005; Szczyglowski et al. 1998), mycorrhizal colonization (Meixner et al. 2005; Solaiman et al. 2000), and disease resistance (Lohar and Bird 2003; Tazawa et al. 2007). Gmnark, harl, and sunn mutants grown in the absence of rhizo- 
bia inoculation have either shorter roots (Buzas and Gresshoff 2007; Schnabel et al. 2005; Szczyglowski et al. 1998), increased numbers of lateral roots compared with wild-type plants (Day et al. 1986; Szczyglowski et al. 1998), or both. The harl and Gmnark mutants are more susceptible to infection by root-knot nematode and Calonectria ilicicola (red crown rot), respectively, indicating that these receptors also function in plant defense (Lohar and Bird 2003; Tazawa et al. 2007). Thus, although these LRR receptor kinases clearly function in both symbiotic and nonsymbiotic pathways, neither the mechanism nor the downstream signals involved have been identified.

To identify potential downstream components of the GmNARK-regulated signaling pathways, we utilized transcriptional profiling to characterize the gene expression in leaves of wild-type plants relative to that of the Gmnark supernodulating mutant following inoculation with rhizobia. This led to the identification of a set of genes whose expression was regulated in the leaves by GmNARK in response to a systemic signal elicited by rhizobia root inoculation. These genes were predicted to be involved in either jasmonic acid (JA) synthesis or response, indicating that the regulation of nodulation by GmNARK may involve transcriptional changes related to hormone signaling. An additional set of genes was identified that were regulated by GmNARK in a rhizobia-independent manner. The putative function of some of these candidates suggests that they may play a role in the receptor-mediated pathways controlling root growth and defense.

\section{RESULTS}

Affymetrix GeneChip soybean genome array analysis.

The Affymetrix GeneChip soybean genome arrays possess probe sets for approximately 37,500 soybean (Glycine max) transcripts. We utilized these arrays to identify genes that are regulated in soybean leaves by GmNARK in either a rhizobia-dependent or rhizobia-independent manner. To identify these two classes of genes, the arrays were probed with RNA isolated from the leaves of wild-type and Gmnark supernodulating mutant (nts 1007) soybean plants. The roots of these plants were either uninoculated or inoculated with Bradyrhizobium japonicum, and RNA was subsequently extracted from the leaf tissue at two different timepoints ( 2 and 5 days posttreatment).

\section{Identification of genes regulated by GmNARK in a rhizobia-independent manner.}

Microarray analyses identified 17 genes that were regulated by GmNARK in a rhizobia-independent manner (Supplementary Table S1). The expression of eight of these candidate genes was predicted to increase in inoculated wild-type soybean leaves relative to inoculated Gmnark mutant leaves. Five of these candidate genes were able to be annotated and are predicted to encode a Toll-interleukin 1 receptor (TIR), nucleotide-binding (NB), LRR protein (57\% similar to potato Gro1-4 AAP44390, E value 7e-48), a FERONIA-like receptor kinase (65\% similar to Arabidopsis FERONIA receptor kinase ABT18096, E value 1e-179), a myosin, a somatic embryo receptor kinase (SERK) or oxidoreductase, and a UDP-glucosyltransferase. The mRNA levels of nine candidate genes were predicted to decrease in wild-type soybean relative to the Gmnark mutant. Annotation of six of these genes revealed that they may encode a glutamate acetyltransferase, kinase (shaggy/ glycogen synthase kinase-3-like), dynamin, hydroxycinnamoyl transferase, tRNA-transglycosylase, and a calcium transporter. Using quantitative real-time polymerase chain reaction (qRTPCR) analysis, we successfully verified the expression of eight

\section{A LeAF}
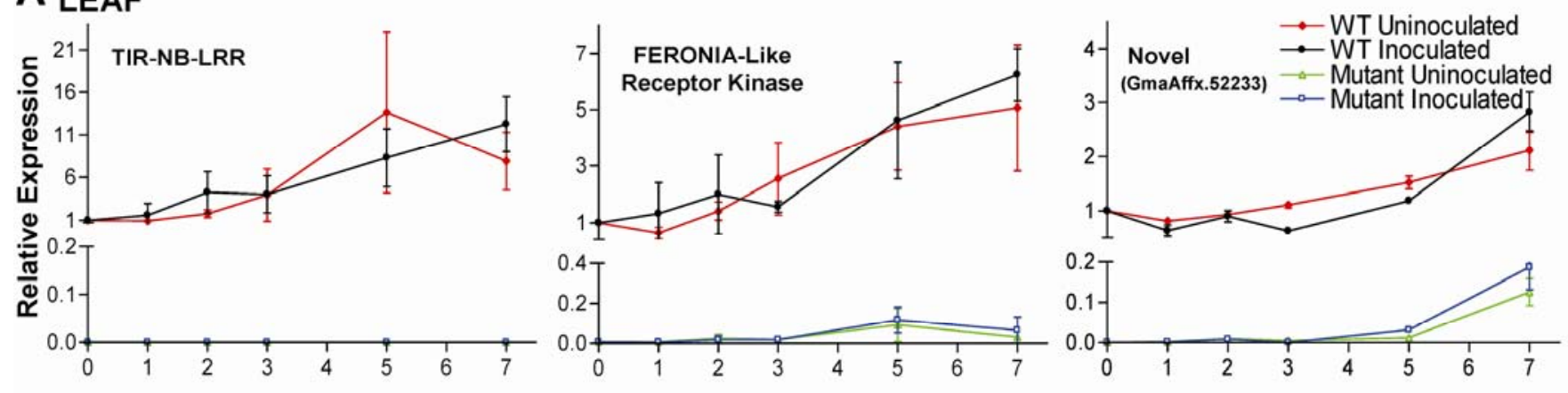

\section{B ROOT}
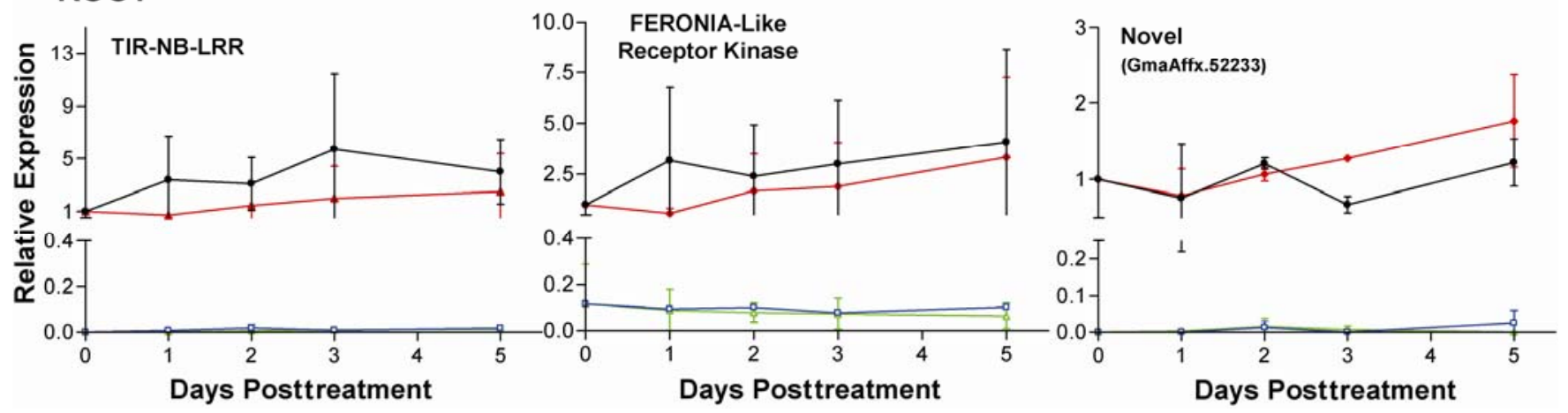

Fig. 1. Leaf and root expression of selected candidate genes regulated by Glycine max nodule autoregulation receptor kinase in a rhizobia-independent manner. A, Quantitative real-time polymerase chain reaction (qRT-PCR) timecourse expression data showing the mean ( \pm standard error of the mean) for three biological replicates (each replicate was grown at a completely different time from one another). B, qRT-PCR timecourse expression data showing the mean and standard deviation for two biological replicates (each replicate was grown at a completely different time from the other). Expression is calculated relative to the wild-type, uninoculated samples at day $0 . \bullet=$ wild type, inoculated; $\bullet=$ wild type, uninoculated; $\square=$ mutant, inoculated; $\triangle=$ mutant, uninoculated. 
of these genes, thereby confirming the accuracy of the Affymetrix GeneChip data (Fig. 1A; Supplementary Table S2).

We also analyzed the root expression of three of these candidate genes, using a detailed timecourse of inoculated and uninoculated wild-type and Gmnark mutant plants. Similar to the expression observed in the leaves, all three genes were found to be regulated by GmNARK in the root (Fig. 1B). Expression of the TIR-NB-LRR gene was barely detectable in Gmnark mutant roots and was estimated to be expressed from 10 - to $>1,260$-fold higher in wild-type roots (Fig. 1B). The gene encoding a FERONIA-like receptor kinase was expressed from 8- to 36-fold higher in the roots of wild-type soybean relative to Gmnark mutant roots (Fig. 1B). The expression of both of these genes increased significantly $(P<0.05)$ in wildtype roots in response to rhizobia inoculation (Fig. 1B). Root expression of the gene corresponding to Affymetrix candidate GmaAffx.5223.1 (no similarity to anything in the database) was also regulated by GmNARK, being expressed 35- to $>140$-fold higher in wild-type roots relative to mutant roots (Fig. 1B). These results suggest that the candidate genes whose leaf expression is controlled by GmNARK in a rhizobia-independent manner are regulated by GmNARK in both the leaf and root and may, therefore, function in GmNARK signaling pathways that are common to both of these plant organs.

\section{Identification of genes regulated by GmNARK in response to rhizobia inoculation.}

Microarray experiments identified four genes that were predicted to be regulated by GmNARK in response to a systemic signal elicited by rhizobia inoculation (Supplementary Table S3). These genes encode a tryptophan synthase beta subunit (TSB; 79\% similar to Arabidopsis TSB NP_974844, E value 4e-158), geranyl diphosphate synthase (GPPS; 67\% similar to
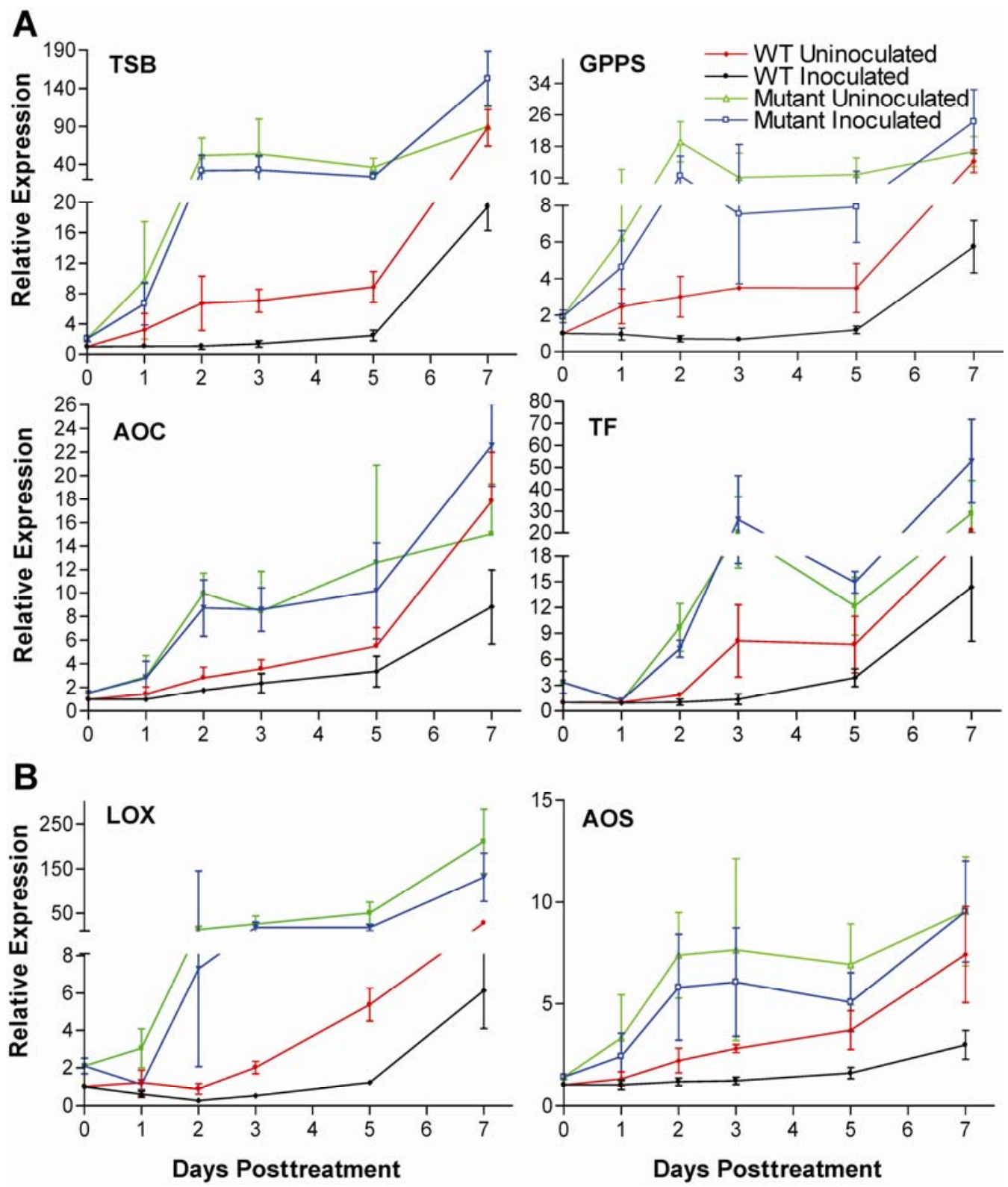

Fig. 2. Leaf expression of selected candidate genes regulated by Glycine max nodule autoregulation receptor kinase in a rhizobia-dependent manner. A, Expression of genes identified by microarray analysis. B, Expression of genes identified using the candidate gene approach. Quantitative real-time polymerase chain reaction timecourse expression data showing the mean ( \pm standard error of the mean) for three biological replicates (each replicate was grown at completely different times from one another). Expression is calculated relative to the wild-type, uninoculated samples at day 0 . $\bullet=$ wild type, inoculated; $\diamond=$ wild type, uninoculated; $\square=$ mutant, inoculated; $\Delta$ mutant $=$ uninoculated. 
Antirrhinum majus GPPS AAS82859, E value 6e-55), allene oxide cyclase (AOC; $82 \%$ similar to MtAOC2, E value 9e-88; Isayenkov et al. 2005), and a transcription factor (TF; 73\% similar to Vitis vinifera Myc2, E value 0.0). The expression of all four genes was predicted to decrease in the leaves of inoculated wild-type soybean plants relative to uninoculated wildtype plants and inoculated $n t s 1007$ plants at both 2 and 5 days posttreatment. To verify the accuracy of the microarray data and to generate a more detailed expression profile for the candidate genes, we performed timecourse analyses of gene expression using qRT-PCR. These independent studies showed that the expression of all four genes was significantly $(P<$ $0.05)$ reduced specifically in wild-type soybean plants following rhizobia inoculation (Fig. 2A). Within 24 to $48 \mathrm{~h}$ after rhizobia root inoculation, leaf expression of the TSB, GPPS, $A O C$, and the $T F$ genes decreased relative to the wild-type, mock-inoculated plants. This repression in gene expression continued over the entire course of the experiment, up to 7 days postinoculation. This timing is consistent with the activation of AON in soybean, which is initiated within $24 \mathrm{~h}$ postinoculation and is fully active after approximately 7 days (Olsson et al. 1989; Pierce and Bauer 1983). The rhizobiainduced repression of TSB, GPPS, AOC, and the TF was abolished in Gmnark mutants (both nts1007 and nts382), indicating that this systemic reduction in gene expression was mediated by this receptor kinase (Fig. 2A).

AOC is an enzyme involved in the synthesis of the hormone JA. The soybean AOC regulated by GmNARK is highly similar to the Medicago truncatula AOC1 and AOC2 proteins (74 and $82 \%$ similarity, respectively) that have been demonstrated to function in JA biosynthesis (Isayenkov et al. 2005). To determine if other genes involved in JA signaling are also regulated by GmNARK, we utilized a targeted gene approach (described below) and qRT-PCR. Three additional genes that were either JA-responsive or may encode key enzymes involved in JA biosynthesis were found to be similarly repressed by GmNARK in response to rhizobia inoculation (Fig. 2B). The expression of these genes, encoding a lipoxygenase (LOX; TC207342), allene oxide synthase (GmAOS1; Kongrit et al. 2007), and dihydroxypterocarpan 6a-hydroxylase (D6aH; Fliegmann et al. 2003) was reduced in wild-type leaves within $48 \mathrm{~h}$ of rhizobia inoculation. Mutations that abolish GmNARK function prevented this reduction in gene expression. Although the inoculation effect on D6aH expression in wild-type plants was relatively moderate (and not statistically significant for the combined timecourse data), it was reproducibly observed at 2 , 3 , and 7 days posttreatment in all three biological replicates.

LOX and AOS are members of multigene families with diverse functions, and only specific members of these families are involved in the synthesis of JA. In plants, LOX are classified as either 9- or 13-LOX according to their positional specificity of the substrate oxygenation (Gardner 1991). These LOX can be further subdivided into two subfamilies, type 1- and type2-LOX, based on their overall sequence characteristics (Shibata et al. 1994). Only the 13-, type2-LOX are believed to be associated with JA synthesis. Similarly, AOS is a member of the CYP74 family, which is part of the cytochrome P450 superfamily of enzymes. Only the CYP74A subfamily is involved in JA biosynthesis. Sequence comparisons indicated that the GmNARK-regulated LOX and AOS (GmAOS1) are likely involved in JA synthesis. The LOX possesses the characteristic 13-LOX space-filling residues (serine and phenylalanine) at the substrate binding pocket (Supplementary Fig. S1), which functionally distinguishes these enzymes from the 9-LOX (Liavonchanka and Feussner 2006). In addition, this LOX is most closely related to 13-, type2-LOX. Two of the most similar LOX from Nicotiana attenuata (81\% similar, E value 3e-121; Halitschke and Baldwin 2003) and Solanum tuberosum (81\% similar, E value 3e-119; Royo et al. 1996) have been experimentally shown to function in JA synthesis. GmAOS1 is clearly a member of the CYP74A subfamily based on primary sequence analysis (Supplementary Fig. S2), and recent biochemical studies further verify that this enzyme likely functions in JA biosynthesis (Kongrit et al. 2007). Detailed expression analysis of two soybean 13-type1-LOX, which are not predicted to be associated with JA synthesis, showed that their expression was not controlled by GmNARK (Hayashi et al. 2008).

\section{Expression of the rhizobia-dependent candidate genes in response to JA treatment.}

It was hypothesized that some of the JA responses occurring in the leaf may involve the additional candidate genes that were found to be regulated by GmNARK in response to rhizobia inoculation. To establish if the differential expression of the candidate genes $T S B, G P P S$, and $T F$ may be due to changes in JA levels in the soybean leaves, we investigated whether the expression of these genes was regulated by JA. Plants were treated with JA by foliar application, and gene expression was analyzed after $0.5,2,6,10$, and $24 \mathrm{~h}$. As shown in Figure 3, expression of all three genes was significantly induced by JA. The timing of JA induction suggests that expression of the $T F$ may peak earlier than the expression of the other genes, indicating that this TF may potentially function to regulate the expression of the other JA-response genes. JA treatment also increased the expression of the $A O S$ and $A O C$ genes (Fig. 3), which is consistent with previous work demonstrating a positive feedback loop for JA biosynthesis (Wasternack et al. 2006). Under the conditions used, the LOX gene was not significantly induced by the JA treatment (Fig. 3). In addition, the soybean $\mathrm{D} 6 \mathrm{aH}$ gene, which was previously reported to be JA-inducible (Fliegmann et al. 2003), showed a significant increase in expression only at $10 \mathrm{~h}$ posttreatment (Fig. 3). The control treatment increased the expression of several genes that may potentially be caused by gene induction in response to low levels of ethanol and surfactant (Tween 20) present in the control solution. Thus, all of the candidates regulated by GmNARK in response to rhizobia inoculation represent JA-responsive genes or enzymes predicted to be involved in JA biosynthesis.

Although the expression of TSB, GPPS, LOX, AOS, AOC, $D 6 a H$, and $T F$ was clearly regulated by GmNARK in response to rhizobia inoculation (Fig. 2A and B, compare wild-type inoculated vs. wild-type uninoculated samples), their expression is significantly higher in the leaves of mutant plants (both inoculated and uninoculated) relative to the uninoculated wild type (Fig. 2A and B). This suggests that GmNARK is reducing the basal JA levels under normal (uninoculated) growth conditions. Mutations that abolish GmNARK function, therefore, result in elevated levels of JA biosynthesis and JA response gene expression. This interpretation is supported by a recent report that shows that the endogenous levels of JA are indeed higher in leaves of the Gmnark mutant compared with wild type under normal growth conditions (discussed below) (Seo et al. 2007).

\section{Rhizobia-dependent candidate gene expression in roots.}

Although GmNARK transcripts are abundant in both the root and shoot (Krusell et al. 2002; Nishimura et al. 2002; Nontachaiyapoom et al. 2007; Schnabel et al. 2005; Yamamoto et al. 2000), grafting experiments have clearly demonstrated that GmNARK functions in the shoot and, most likely, in the leaf, to regulate nodulation (Delves et al. 1986, 1992). Therefore, downstream signals of GmNARK that are involved in AON signaling should be regulated in an organ-specific manner (i.e., in the shoot but not in the root). qRT-PCR analyses on 
six of the rhizobia-dependent candidate genes involved in JA signaling showed that they were all expressed at a similar level in the roots of wild-type soybean and the Gmnark supernodulating mutants $n t s 1007$ and $n t s 382$ (Fig. 4). LOX, AOS, and $A O C$ expression increased moderately (not statistically signifi- cant with $P<0.05$ ) at 1 day postinoculation, suggesting that JA levels in the root may increase transiently in response to rhizobia treatment. Thus, GmNARK controls the expression of $L O X, A O S, A O C, T S B, G P P S$, and $T F$ in soybean leaves but not in roots, and this tissue-specific regulation is dependent on a

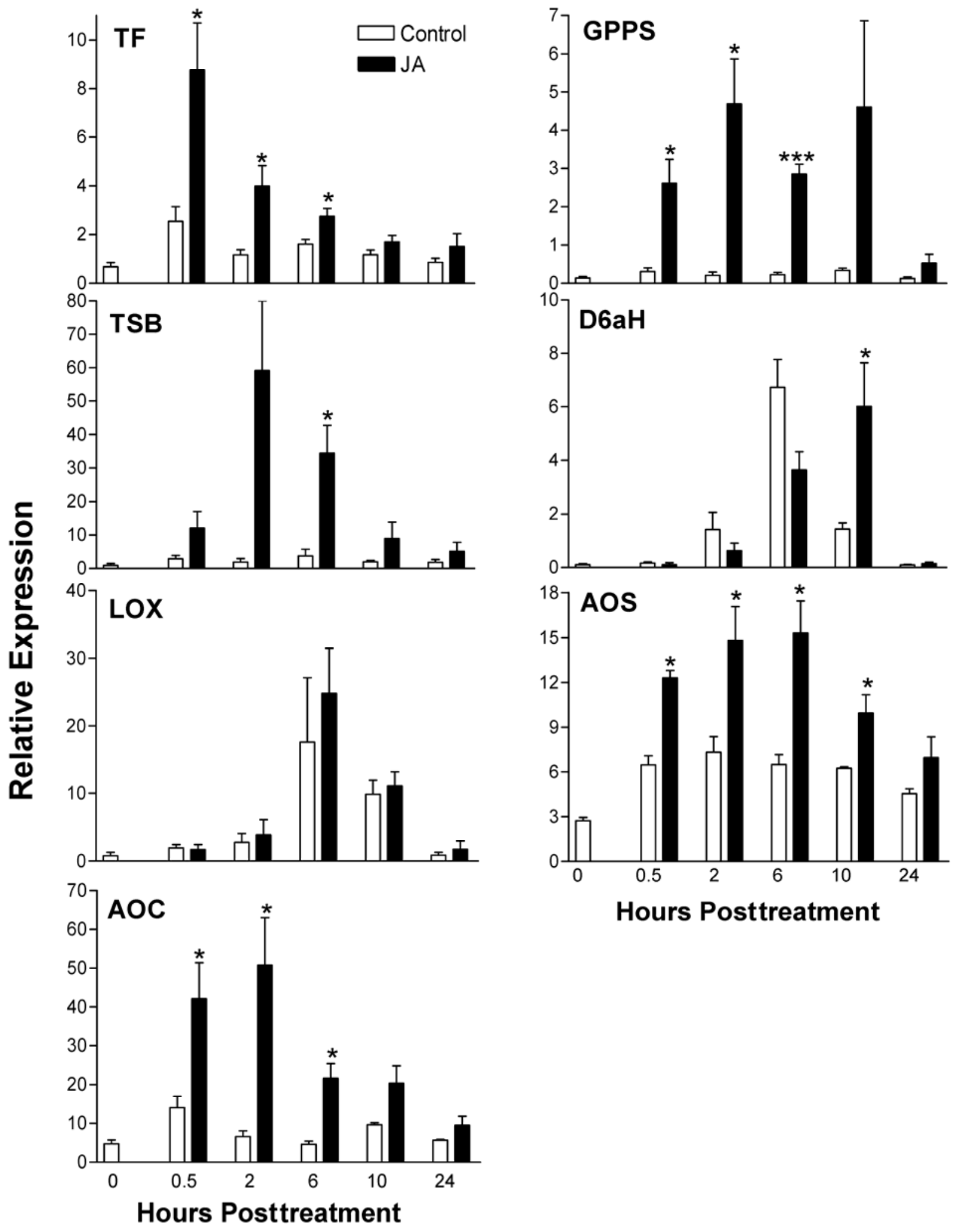

Fig. 3. Expression of candidate genes in response to jasmonic acid (JA) treatment. Quantitative real-time polymerase chain reaction timecourse expression data showing the mean ( \pm standard error of the mean) for three biological replicates. JA treatment was carried out by spraying soybean leaves with $100 \mu \mathrm{M}$ JA (Sigma) in $0.1 \%$ ethanol, $0.05 \%$ Tween 20 . Control plants were sprayed with $0.1 \%$ ethanol, $0.05 \%$ Tween 20 . Expression is calculated relative to percent actin. Statistical significance was determined by Student's $t$ test. * indicates $P<0.05$; *** indicates $P<0.001$. 
rhizobia-induced long-distance signal. This pattern of expression is consistent with the hypothesis that these genes play a role in GmNARK signaling and the long-distance regulation of nodulation. As described above, root expression was also analyzed in detail for three of the candidate genes that were differentially expressed in the leaves in a rhizobia-independent manner. All three of these genes were found to be regulated by GmNARK in the roots (Fig. 1B). These data further illustrate that the genes controlled by GmNARK fall into two distinct classes: i) those regulated in an organ-dependent manner (i.e., leaves and not root) in response to a rhizobia-induced longdistance signal and ii) those regulated by GmNARK in both the root and shoot in a rhizobia-independent manner.

\section{Foliar application of a JA biosynthesis inhibitor reduces} nodulation specifically in the supernodulating mutant.

The gene expression data indicates that the regulation of nodulation by GmNARK involves a reduction in leaf JA signaling in response to rhizobia root inoculation. Thus, the elevated levels of JA signaling in the Gmnark mutant shoot would be predicted to play a role in the supernodulation phenotype. We investigated the functional importance of JA signaling in the long-distance control of nodulation by treating the leaves of soybean plants (wild type and nts 1007) with a well-established chemical inhibitor (n-propyl gallate) of JA biosynthesis. Foliar application of propyl gallate significantly $(P=0.0004)$ decreased nodulation in the Gmnark mutant but had no effect on wild-type plants (Fig. 5A). Propyl gallate treatment did not affect root development (Fig. 5B), indicating that the reduction in nodulation was not due to a nonspecific inhibition of root growth. The specificity of propyl gallate was further demonstrated by the fact that this chemical had no effect on wild-type plants, while AON is functional and JA signaling is reduced in response to rhizobia inoculation.

\section{DISCUSSION}

The following lines of evidence indicate that a GmNARKmediated reduction in JA signaling in the leaves plays a significant role in the AON signal transduction pathway: i) GmNARKmediated signaling reduced the expression of genes encoding key enzymes of the JA biosynthetic pathway in response to a rhizobia-induced long-distance signal, ii) GmNARK-mediated signaling reduced the expression of JA-regulated genes in response to a rhizobia-induced long-distance signal, iii) endogenous JA levels are elevated in the leaves of Gmnark mutant
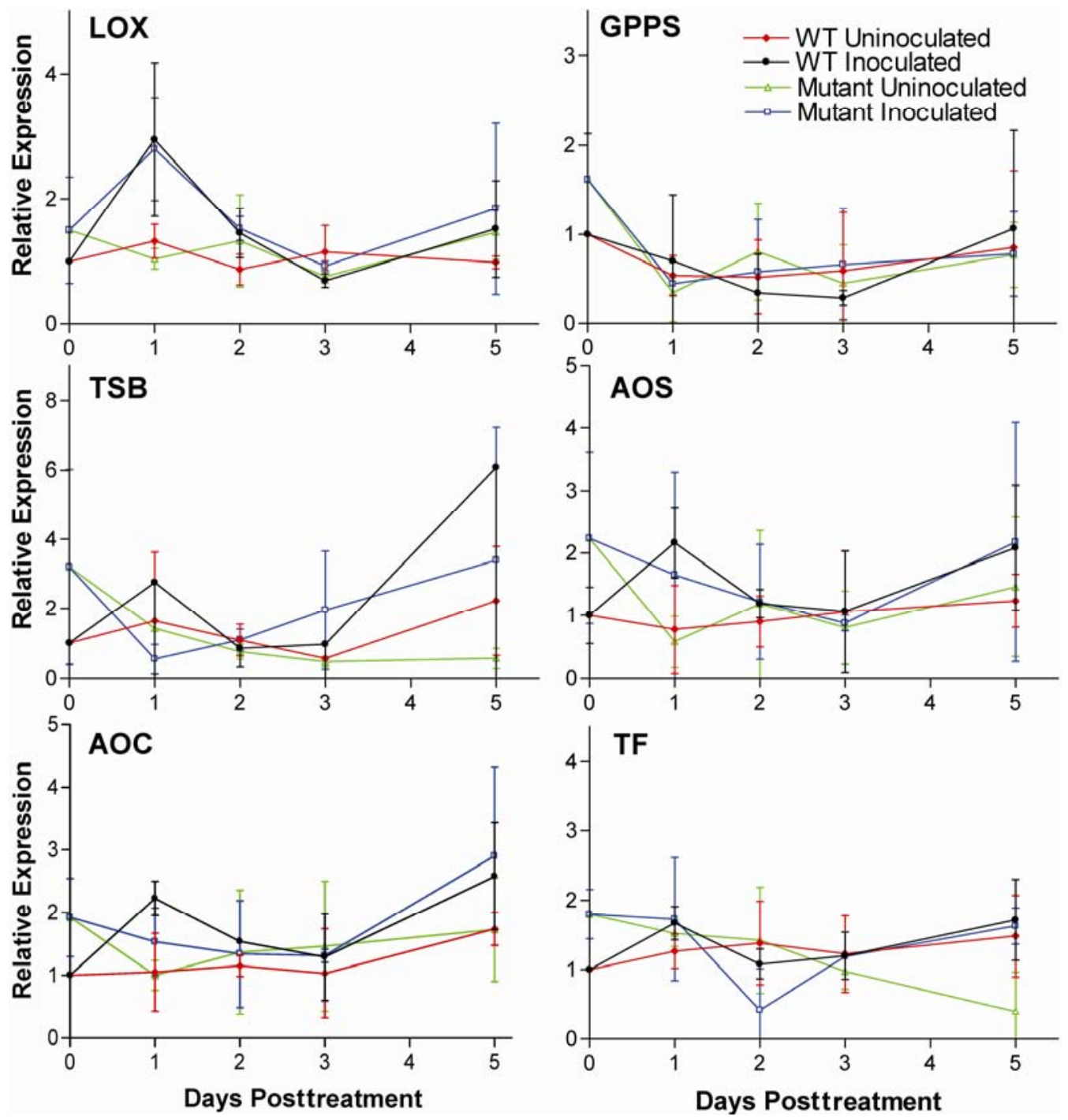

Fig. 4. Root expression of candidate genes regulated by Glycine max nodule autoregulation receptor kinase in the leaves in a rhizobia-dependent manner. Quantitative real-time polymerase chain reaction timecourse expression data showing the mean and standard deviation for two biological replicates (each replicate was grown at a completely different time from the other). Expression is calculated relative to the wild-type, uninoculated samples at day $0 . \bullet=$ wild type, inoculated; $\diamond$ = wild type, uninoculated; $\square$ mutant, inoculated; $\triangle=$ mutant, uninoculated. 
plants (Seo et al. 2007), iv) GmNARK-mediated signaling reduced the expression of the JA synthesis and response genes in an organ-dependent manner, and v) foliar application of a JA biosynthesis inhibitor reduced nodulation specifically in the Gmnark mutant.

\section{GmNARK regulation of JA signaling and AON.}

JA is synthesized via the octadecanoid pathway through the sequential action of the chloroplast-localized enzymes LOX, AOS, and AOC, which convert linolenic acid to 12-oxo-phytodienoic acid (OPDA). OPDA, which can function as a signal molecule independently of JA (Taki et al. 2005), is converted to JA in the peroxisomes by reduction and three cycles of $\beta$ oxidation. AOS is a particularly important enzyme, as it represents the first committed step in JA biosynthesis, and overexpression of this enzyme can result in elevated levels of JA accumulation (Harms et al. 1995; Laudert et al. 2000). As detailed above, only specific LOX (13-, type2-LOX) and AOS (CYP74A subfamily) enzymes function in JA biosynthesis (Gardner 1991; Norton et al. 2007; Shibata et al. 1994). Sequence analysis, functional studies (on related genes from other plants), and previous biochemical characterization (GmAOS1) indicate that the LOX, AOS, and AOC that are regulated by GmNARK likely function in the synthesis of JA.

The four additional genes regulated by GmNARK in response to rhizobia inoculation were found to be rapidly induced by JA treatment. Three of these genes encode enzymes (TSB, GPPS, and $\mathrm{D} 6 \mathrm{aH}$ ) involved in secondary metabolism, while the other candidate gene encodes a MYC TF (E value 0.0 to $\mathrm{Myc} 2$ from Vitis vinifera). Additional studies will be required to determine if this TF is functionally related to the MYC TF that control JA signaling in tomato and Arabidopsis (Boter et al. 2007). The coordinate regulation of genes that are either predicted to synthesize JA or that respond to this hormone indicates that GmNARK is likely controlling JA signaling in response to the systemic signal elicited by rhizobia inoculation. Recent data showing that endogenous JA levels are higher in the leaves of Gmnark mutant plants relative to wild type further demonstrates that GmNARK represses JA levels in the shoot (Seo et al. 2007). Although the experiments by Seo and associates (2007) demonstrate that GmNARK is involved in the regulation of JA synthesis, their work does not allow them to show that this regulation is related to AON signaling. This is because they did not compare the JA levels in inoculated vs. uninoculated wild-type leaves, and their limited gene expression data prevented them from identifying any of the JA-biosynthesis and JA-responsive genes that are controlled by GmNARK in response to rhizobia inoculation. Consequently, they mistakenly conclude that differences in JA levels between the Gmnark mutant and wild type are unrelated to nodulation. Nevertheless, their observation that JA levels are elevated in the leaves of uninoculated mutant plants relative to wild type is consistent with our gene expression data showing that GmNARK “dampens” JA signaling under normal (uninoculated) growth conditions. Most importantly, their data provides additional endogenous verification that GmNARK functions in the repression of JA signaling. It is possible that a developmentally regulated elevation of JA levels is responsible for the dramatic increase in expression of the candidate genes in the Gmnark mutant plants (both inoculated and uninoculated) at 2 to 3 days posttreatment (Fig. 2A and B). In the uninoculated wild type this developmental change is not as significant, potentially due to a GmNARK-mediated reduction in the basal JA levels.

The organ-specific regulation of the JA biosynthesis and response genes by GmNARK provides critical data suggesting that the gene-expression changes are in fact biologically relevant to the AON signal transduction pathway. Consistent with the established model of AON, these experiments demonstrate that GmNARK in the leaves (but not in the roots) is responding to a long-distance signal that is generated by rhizobia inoculation. Mutations that abolish GmNARK activity prevented the organ-specific repression of these genes. The JA biosynthesis and response genes controlled by GmNARK appear to be distinct from the second class (rhizobia independent) of genes regulated by this receptor kinase. Leaf expression of the rhizobia-independent genes is not affected by inoculation, and detailed analyses of several of these candidates revealed that they are not differentially expressed in an organ-specific manner.

Pharmacological data obtained by using an inhibitor of JA biosynthesis (n-propyl gallate) provided functional support for the endogenous gene expression data. Foliar application of propyl gallate significantly reduced nodulation specifically in Gmnark mutant plants. Propyl gallate is a well-established LOX inhibitor (Parish and Leopold 1978) and has been shown to block the synthesis of the JA precursor OPDA (Peña Cortés et al. 1993). This chemical has been used in numerous studies to verify the role of JA in wound and elicitor-induced responses of
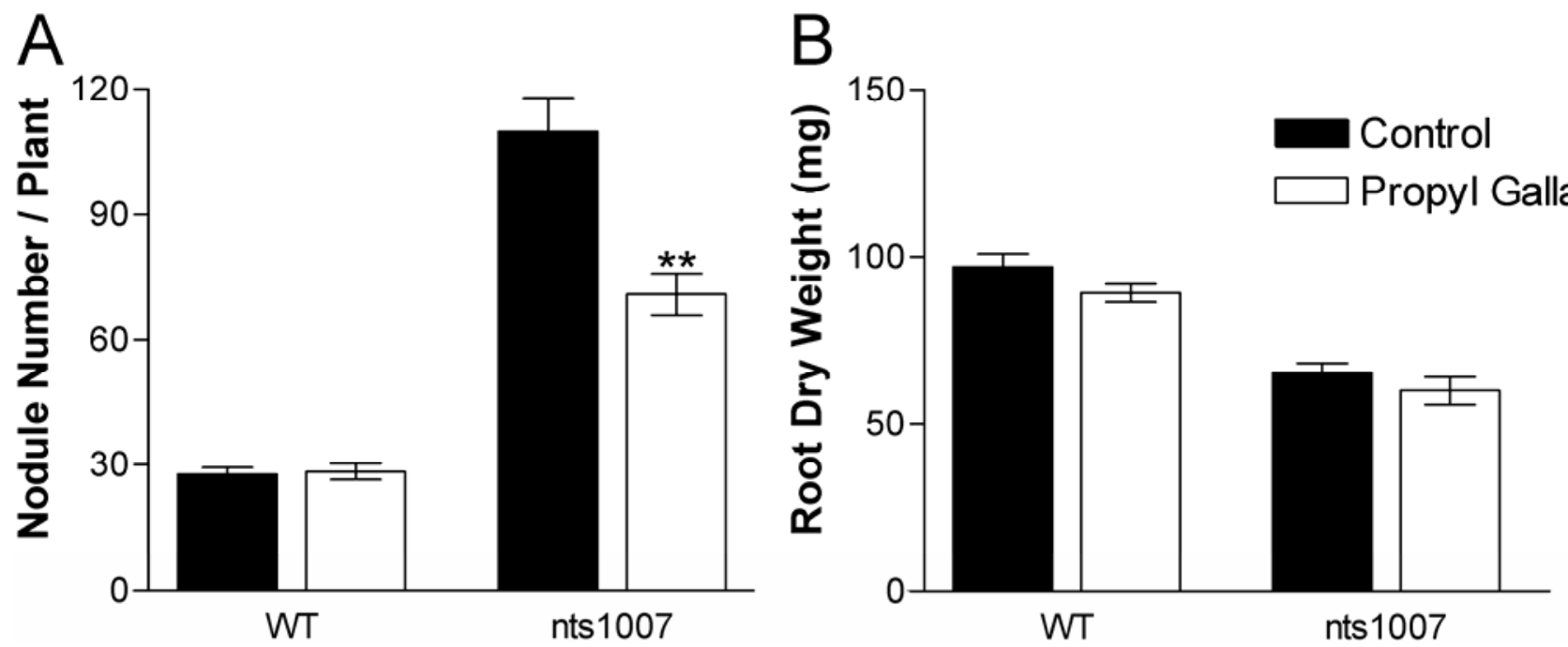

Fig. 5. Foliar application of the jasmonic acid (JA) biosynthesis inhibitor n-propyl gallate reduces nodulation specifically in the supernodulating mutant. Shoots were treated with either $1 \mathrm{mM}$ n-propyl gallate in $0.2 \mathrm{mM}$ potassium phosphate $(\mathrm{pH} 6.8), 0.05 \%$ silwet or with potassium phosphate or silwet alone (control). Data represent the mean ( \pm standard error of the mean) for $\mathbf{A}$, nodule number and $\mathbf{B}$, root dry weight when $n=13$ to 18 . Statistical significance was determined by Student's $t$ test. ** indicates $P<0.001$. 
various plants (Ellard-Ivey and Douglas 1996; Koch et al. 1999; Nishiuchi et al. 1997; Peña Cortés et al. 1993; Staswick et al. 1991). It is highly unlikely that propyl gallate is inhibiting nodulation nonspecifically in the supernodulating mutant, because it did not have any negative effects on root growth or on nodulation in wild-type plants (Fig. 5A and B). For this reason, the use of propyl gallate to investigate the role of JA in AON signaling is likely to be more informative than the use of exogenous hormone application. Plant growth and development is significantly inhibited by JA treatment (Feys et al. 1994; Nakagawa and Kawaguchi 2006; Staswick et al. 1992). Biotic and abiotic factors that reduce plant growth (especially primary and lateral root development) often result in a reduction in nodulation (Chen et al. 2003; Velagaleti and Marsh 1989; Zablotowicz and Reddy 2004). In addition, JA is a potent inducer of systemic plant-defense responses (Dong 1998; Truman et al. 2007) that may inhibit rhizobia infection through signaling pathways that are unrelated to AON. Thus, the induction of plant defense or inhibition of plant growth caused by JA application would preclude any meaningful interpretations on AON signaling.

Although foliar application of propyl gallate significantly reduced nodulation in the Gmnark mutant, it did not reduce nodule number to wild-type levels. This may potentially be due to the technical difficulty in delivering the inhibitor into the leaf vasculature (the likely site of action; Nontachaiyapoom et al. 2007) for a sustained period of time. However, based on studies in various legumes demonstrating that AON may involve changes in polar auxin transport and brassinosteroid signaling, it is likely that JA is functioning as part of a network of hormones to control nodule development.

\section{Hormones and the long-distance regulation of nodulation.}

The hormones JA, auxin (indole 3-acetic acid), and brassinosteroid (BR) have previously been associated with the long-distance regulation of nodulation in various legumes (Ferguson et al. 2005; Nakagawa and Kawaguchi 2006; Terakado et al. 2005; van Noorden et al. 2006). In M. truncatula, there is evidence that nodulation may be controlled by auxin transport from the shoot to the root (van Noorden et al. 2006, 2007). The hormone BR has also been associated with nodulation. However, it is reported to have contrasting roles in different legumes. Grafting studies utilizing a BR-deficient mutant in pea revealed that reduced levels of BR in the shoot led to decreased nodulation in wild-type roots (Ferguson et al. 2005). In soybean, however, foliar application of BR or an inhibitor of BR synthesis indicated that nodulation is negatively controlled by this hormone (Terakado et al. 2005).

Foliar application of JA has been reported to inhibit nodulation in both wild-type and supernodulating L. japonicus and soybean (Nakagawa and Kawaguchi 2006; Seo et al. 2007). These results suggesting a negative role for JA in the long-distance regulation of nodulation, however, have not been substantiated by any endogenous data on JA signaling and may be caused by the pleiotropic effects associated with exogenous hormone application. To the contrary, the endogenous evidence strongly indicates that JA is positively associated with both nodulation and the related symbiotic interaction with arbuscular mycorrhizal (AM) fungi (Hause et al. 2002; Isayenkov et al. 2005; Meixner et al. 2005; Seo et al. 2007; Stumpe et al. 2005; and present data). AM colonization is relevant to the study of the rhizobia-legume interaction, because these two symbiotic associations involve similar mechanisms for early infection and the subsequent control of infection via AON (Catford et al. 2003; Kinkema et al. 2006; Meixner et al. 2005; Shrihari et al. 2000; Solaiman et al. 2000). Consistent with our gene expression data, Seo and associates (2007) showed that the endogenous levels of JA are elevated in leaves of the Gmnark mutant. The endoge- nous JA levels and expression of JA biosynthesis genes increases in roots in response to mycorrhization (Hause et al. 2002; Isayenkov et al. 2005; Meixner et al. 2005; Stumpe et al. 2005), and a reduction in JA accumulation results in a strong decrease in colonization and arbuscule formation by AM (Isayenkov et al. 2005).

Thus, various lines of evidence suggest that hormones such as $\mathrm{JA}$, auxin, and BR are involved in the long-distance regulation of nodulation. Our data provide the first evidence that the receptor-mediated control of AON may involve the transcriptional regulation of genes involved in hormone signaling. Do these various hormones function as the SDI that has been proposed to suppress nodulation during AON signaling? The simplest interpretation of the AON model is that the SDI represents a molecule that is produced in the leaves of wild-type plants in response to rhizobia inoculation. Mutations in the AON receptor kinases are predicted to abolish the production of the SDI and, therefore, result in a supernodulation phenotype. This model, together with our current data, suggests that JA signaling may function as a repressor of the SDI. However, in light of the evidence that a number of different hormones may function in the long-distance regulation of nodulation in various legumes, it is more likely that $\mathrm{AON}$ signaling involves a coordinated response involving both the production of the SDI and changes in hormone signaling. In soybean, we propose that these hormone changes include a reduction in JA signaling that is mediated by GmNARK. The role of JA in systemic signaling is well established (Schilmiller et al. 2005; Truman et al. 2007), and its effect on nodulation may be caused by reduced transport of JA (or its derivatives) from the shoot to the root, as suggested for the hormone auxin (van Noorden et al. 2006). Reduced levels of JA in developing nodule primordia may potentially suppress further nodule development through changes in either flavonoid biosynthesis, carbohydrate supply, or both as discussed by Isayenkov and associates (2005).

\section{Nonsymbiotic pathways regulated by GmNARK.}

Microarray analysis also identified 17 genes that were controlled by GmNARK in a rhizobia-independent manner. Analysis of a subset of these genes indicated that they were regulated by GmNARK in both the root and shoot. This discovery further suggests that we have indeed identified two different classes of genes; those regulated by GmNARK in the shoot (but not the root) and likely involved in AON signal transduction, and a second class of genes that may function in GmNARK-regulated processes that are independent of nodulation. Of the 11 rhizobia-independent candidate genes that were able to be annotated, some of these can be classified as having a potential role in metabolism or plant defense.

\section{Metabolism.}

Candidates that have proposed functions in secondary metabolism include a putative UDP-glucosyltransferase, glutamate acetyltransferase, and hydroxycinnamoyl transferase. Glucosyltransferases transfer nucleotide diphosphate-activated sugars to plant hormones and all major classes of secondary metabolites, such as flavonoids, phenolics and alkaloids (Bowles et al. 2005; Ross et al. 2001). This modification has been shown to regulate various properties of these molecules, such as their stability, activity, and transport within the plant. Analysis of glucosyltransferase function in Medicago sativa (alfalfa) revealed that plants expressing antisense RNA to a UDP-glucosyltransferase from pea (PsUGT1) had an increased number of lateral roots and reduced root growth (Woo et al. 2003). The function of this glucosyltransferase is potentially mediated by auxin as ectopic expression of PsUGT1 altered auxin distribution in the root. The Gmnark, harl, and sunn mutants have 
either shorter roots (Schnabel et al. 2005; Szczyglowski et al. 1998), increased numbers of lateral roots, or both compared with wild-type plants (Day et al. 1986; Szczyglowski et al. 1998). Grafts between wild-type L. japonicus and the supernodulating harl mutant showed that the shoot genotype can control both the supernodulation and short root/increased lateral root phenotypes of harl (Buzas and Gresshoff 2007; Krusell et al. 2002). Buzas and Gresshoff (2007) have also shown that the root genotype influences the nonsymbiotic root phenotypes of harl. The UDP-glucosyltransferase controlled by GmNARK was expressed approximately 10- to 50-fold higher in the leaves of wild-type plants relative to Gmnark. qRT-PCR also showed that this gene was expressed approximately twofold higher in wild-type roots compared with mutant roots (data not shown). Based on the demonstrated function of PSUGT1, it is possible that the reduced expression of a UDP-glucosyltransferase is associated with the nonsymbiotic root phenotypes of Gmnark, harl, and sunn.

\section{Plant defense.}

Increased susceptibility of the L. japonicus harl-1 and soybean Gmnark mutants to infection by root-knot nematode and Calonectria ilicicola (red crown rot), respectively, indicate that these receptor kinases likely function in plant defense (Lohar and Bird 2003; Tazawa et al. 2007). One of the genes showing the most significant differential expression between wild-type and Gmnark mutant plants is predicted to encode a TIR-NBLRR disease resistance-like protein. This gene was expressed significantly higher in both the leaves and roots of wild-type plants relative to the Gmnark mutant (Fig. 1A and B). Expression of the TIR-NB-LRR gene in wild-type plants is constitutive, although expression in the root increased slightly in response to rhizobia treatment. This suggests that the TIR-NBLRR protein may function in the perception and early signaling to infection by microbial pathogens in both the shoot and root. One of the proteins that showed the highest sequence similarity to the predicted soybean TIR-NB-LRR protein is the potato Gro1-4 (57\% similar, E value 7e-48), which functions in nematode resistance (Paal et al. 2004). These data indicate that the AON receptor kinases may play an indirect role in plant defense through the transcriptional regulation of resistance genes. Increased expression of the glucosyltransferase gene may also be associated with enhanced disease resistance in wild-type soybean relative to the Gmnark mutant, as previous work has shown that reduced expression of a tobacco glucosyltransferase results in an increased susceptibility to viral infection (Chong et al. 2002).

In conclusion, GmNARK is similar to the Arabidopsis receptor kinase CLV1, which controls shoot apical meristem development, at least in part, through the transcriptional regulation of genes involved in cytokinin signaling (Leibfried et al. 2005). Our data suggest that the regulation of nodule meristem development by GmNARK involves the transcriptional regulation of genes involved in JA signaling. Considering the close relationship between symbiosis and disease, it is not surprising to find that this key regulator of the AON signal transduction pathway may also play a role in plant defense. Future work will help to elucidate the functional importance of the genes acting downstream of this receptor kinase and may shed light on the relationships between AON and other signaling networks.

\section{MATERIALS AND METHODS}

\section{Plant growth and RNA isolation.}

All soybean seeds were surface-sterilized for approximately $16 \mathrm{~h}$, using chlorine gas. Samples used for microarray analysis were prepared by growing wild-type (Bragg cultivar) and nts1007 seedlings in growth pouches (Mega International, West St. Paul, MN, U.S.A.) wet with nitrogen-free Broughton and Dilworth nutrient solution (Broughton and Dilworth 1971). For the inoculated samples, seedling roots were treated with Bradyrhizobium sp. strain CB1809 at 3 days postsowing. Soybean leaf (including the shoot apical meristem region but excluding the cotyledons) samples were subsequently harvested from uninoculated and inoculated seedlings at 2 and 5 days posttreatment (these two timepoints fall within the timing of AON activation in soybean). Two independent biological replicates (conducted at different times) were performed to compare inoculated seedlings of wild type and nts1007 (at both 2 and 5 days postinoculation), and one of these replicates also included uninoculated wild-type seedlings to identify those genes that are differentially expressed in response to rhizobia inoculation. Germination and seedling growth was carried out in a plant growth chamber (Conviron, Winnipeg, Canada) maintained at $28^{\circ} \mathrm{C}$ day and $25^{\circ} \mathrm{C}$ night temperatures, with $80 \%$ humidity and a $16-\mathrm{h}$ photoperiod. RNA was prepared using a Nucleospin RNA plant kit according to the manufacturer's instructions (Macherey-Nagel, Oensingen, Switzerland), and the integrity and concentration were assessed using an Agilent bioanalyser 2100 (Santa Clara, CA, U.S.A.).

To verify the accuracy of the microarray data and to generate a more detailed expression profile for some of the candidate genes, we performed timecourse analyses of gene expression using qRT-PCR. To obtain a rigorous and truly independent verification of gene expression, we utilized the following measures for our timecourse studies. First, the plants were grown in pots containing vermiculite in a temperature-controlled glasshouse instead of using growth pouches, as for the microarray analyses. In addition the seedlings were treated (rhizobia root inoculation or mock-inoculated) at 10 days postsowing instead of at 3 days postsowing. The rationale for utilizing different growth conditions is based on the assumption that genes that are regulated by GmNARK and are biologically relevant should be differentially expressed in both pouch- and pot-grown seedlings. In addition, since $A O N$ is inducible at both 3 and 10 days postsowing, candidates involved in AON signaling should be differentially expressed under both conditions. Plants used for the timecourse analysis of gene expression were grown in pots containing vermiculite in a temperaturecontrolled glasshouse maintained at $28^{\circ} \mathrm{C}$ with a photoperiod of $16 \mathrm{~h}$. Seedlings were treated with Bradyrhizobium sp. strain CB1809 (grown in YMB media [0.2\% mannitol, 0.04\% yeast extract, $0.2 \% \mathrm{MgSO}_{4}-7 \mathrm{H}_{2} 0,0.1 \% \mathrm{NaCl}, 0.05 \% \mathrm{~K}_{2} \mathrm{HPO}_{4}, \mathrm{pH}$ 6.8]) or an equivalent dilution of $\mathrm{YMB}$ (uninoculated controls) at 10 days postsowing. Leaf (excluding cotyledons) and root tissue was simultaneously harvested from approximately four plants at $0,1,2,3,5$, and 7 days posttreatment. Three independent biological replicate timecourse experiments were carried out utilizing two different mutant alleles of GmNARK (two experiments were conducted with nts1007 and one experiment with $n t s 382$ ). We utilized two different mutant alleles of $G m N A R K$ to ensure that changes in gene expression were not caused by secondary mutations within the regulatory regions of the candidate genes. In addition, each of the biological replicates was grown at a completely separate time from each of the other replicates. Timecourse data were analyzed statistically by two-way analysis of variance with posthoc Bonferroni correction. A $P$-value of $<0.05$ indicated a significant difference.

\section{Affymetrix GeneChip hybridization and candidate gene identification.}

Approximately $7.5 \mu \mathrm{g}$ of total RNA was labeled using the Affymetrix one cycle cDNA synthesis kit (Millenium Sciences, Surry Hills, Australia), and the cDNA was subsequently cleaned 
using the Affymetrix GeneChip sample cleanup kit. The in vitro transcription (IVT) amplification and biotin-labeling of cRNA was performed using the Affymetrix IVT labeling kit, and cRNA was subsequently cleaned using the GeneChip sample cleanup kit. A total of $20 \mu \mathrm{g}$ of labeled cRNA was fragmented to the 50to 200-bp size range and quality control checked with a Bioanalyser 2100 using the NanoChip protocol. Hybridization to the Affymetrix GeneChip soybean genome array was performed as described in the Affymetrix technical analysis manual. The GeneChips were washed and stained with streptavidinphycoerythrin using the Affymetrix fluidics station 450 and were scanned using the Affymetrix GeneChip scanner 3000.

Data analysis was performed by pairwise comparisons of GeneChips using dCHIP ( $\mathrm{Li}$ and Wong 2001). Comparisons were performed to determine a lower $90 \%$ confidence bound (LCB) value, which represents a conservative estimate of the fold change. To identify genes that may be differentially expressed in the leaves of wild-type plants relative to the Gmnark supernodulating mutant and are also responsive to rhizobia root inoculation, six comparisons were performed, i.e., wildtype inoculated (WTI) vs. mutant inoculated (MI) plants at 2 and 5 days posttreatment (two biological replicates each) and WTI vs. wild-type uninoculated (WTU) plants at 2 and 5 days posttreatment. Genes with a LCB value of 1.5 -fold or higher for all six comparisons were selected for further analysis. The identification of genes that may be differentially expressed in the leaves of wild-type plants relative to the Gmnark supernodulating mutant in a rhizobia-independent manner was performed using the following eight pairwise comparisons: WTI vs. MI plants at 2 and 5 days posttreatment (two biological replicates each); WTU vs. MI plants at 2 and 5 days posttreatment; WTI vs. WTU at 2 and 5 days posttreatment. Genes with a LCB value of twofold or higher for all six comparisons between wild-type and mutant plants and that were not differentially expressed twofold or more between WTI and WTU samples were selected for further analysis.

The identification of additional candidate genes that were regulated by GmNARK in a rhizobia-dependent manner was performed by analyzing the microarray expression data for selected genes that were predicted to be involved in JA biosynthesis and secondary metabolism. Genes that were predicted to be differentially expressed at least 1.5 -fold in at least two of the above comparisons were selected for further analysis by qRT-PCR.

\section{Candidate gene sequence characterization.}

Annotation information was generated using blastp, blastx, tblastx, or blastn searches of The Institute for Genomic Research (TIGR) gene indices and the National Center for Biotechnology Information (NCBI) database. The entire coding sequence was obtained for Gma.736 and Gma.9069 by characterizing products from $5^{\prime}$ rapid amplification of cDNA ends (Ambion, Austin, TX, U.S.A.) and bacterial artificial chromosome (BAC) clones, respectively. Additional sequence information was obtained for candidate gene GmaAffx.27554 through the isolation and sequence analysis of BAC clones. Sequence data for Gma.9069 and Gma.736 can be found in the GenBank database under accession numbers EU399509 and EU399510, respectively. Sequence similarities presented for the candidates are based on database searches with the predicted protein sequences.

\section{qRT-PCR.}

First-strand cDNA was synthesized from $1 \mu \mathrm{g}$ of total leaf or root RNA using SuperscriptIII and following the manufacturer's instructions (Invitrogen, Carlsbad, CA, U.S.A.). The cDNA templates were diluted and added to SYBR green PCR master mix (Applied Biosystems, Foster City, CA, U.S.A.) containing $0.2 \mu \mathrm{m}$ of each primer. qRT-PCR was performed using an ABI PRISM 7900HT or 7000 (Applied Biosystems) and the following parameters: $95^{\circ} \mathrm{C}$ for $10 \mathrm{~min}$, followed by 35 cycles of $95^{\circ} \mathrm{C}$ for $15 \mathrm{~s}$ and $60^{\circ} \mathrm{C}$ for $1 \mathrm{~min}$. A melting curve profile from 60 to $95^{\circ} \mathrm{C}$ was conducted at the end of each PCR to verify the specificity of the reaction. Individual values for each sample were generated by averaging two technical replicates, which typically varied by less than 0.5 cycles. Primers were designed using Primer Express (Applied Biosystems). Samples were normalized using soybean actin (V00450).

\section{JA inhibitor treatments.}

Seedling shoots were immersed daily for 9 days in a solution of either $1 \mathrm{mM}$-propyl gallate, $0.2 \mathrm{mM}$ potassium phosphate (pH6.8), $0.05 \%$ silwet or potassium phosphate or silwet alone (control), starting 1 day prior to rhizobia inoculation. Seedlings were inoculated with Bradyrhizobium sp. strain CB1809 at 10 days postsowing. Nodule numbers were determined at either 12 (nts1007) or 13 (wild type) days postinoculation.

\section{ACKNOWLEDGMENTS}

Microarray hybridizations and gene sequencing were conducted at the Australian Genome Research Facilities in Melbourne and Brisbane, respectively. Soybean BAC clones were obtained from the Clemson University Genomics Institute (CUGI). We thank B. Simpson for help with qRTPCR, and J. Hadler, B.-Y. Zhang, A. Izadi-Drabandi, B. Ferguson, and S. Schaarschmidt for their technical assistance. Financial support came from the ARC Centre of Excellence program, the University of Queensland Strategic Fund, the BACS Faculty, and the Queensland Government Smart State Initiative.

\section{LITERATURE CITED}

Bauer, W. D. 1981 Infection of legumes by rhizobia. Annu. Rev. Plant Physiol. 32:407-449.

Boter, M., Ruíz-Rivero, O., Abdeen, A. and Prat, S. 2007. Conserved MYC transcription factors play a key role in jasmonate signaling both in tomato and Arabidopsis. Genes Dev. 18:1577-1591.

Bowles, D., Isayenkova, J., Lim, E. K., and Poppenberger, B. 2005. Glycosyltransferases: Managers of small molecules. Curr. Opin. Plant Biol. 8:254-263.

Broughton, W. J., and Dilworth, M. J. 1971. Control of leghaemoglobin synthesis in snake beans. Biochem. J. 125:1075-1080.

Buzas, D. M., and Gresshoff, P. M. 2007. Short and long distance control of root development by LjHARI during the juvenile stage of Lotus japonicus. J. Plant Physiol. 164:452-459.

Caetano-Anollés, G., and Gresshoff, P. M. 1991. Plant genetic control of nodulation. Annu. Rev. Microbiol. 45:345-382.

Carroll, B. J., McNeil, D. L., and Gresshoff, P. M. 1985a. Isolation and properties of soybean [Glycine $\max (\mathrm{L}$.) Merr.] mutants that nodulate in the presence of high nitrate concentrations. Proc. Natl. Acad. Sci. U.S.A. 82:4162-4166.

Carroll, B. J., McNeil, D. L., and Gresshoff, P. M. 1985b. A supernodulation and nitrate tolerant symbiotic (nts) soybean mutant. Plant Physiol. 78:34-40.

Catford, J. G., Staehelin, C., Lerat, S., Piché, Y., and Vierheilig, H. 2003. Suppression of arbuscular mycorrhizal colonization and nodulation in split-root systems of alfalfa after pre-inoculation and treatment with Nod factors. J. Exp. Bot. 54:1481-1487.

Chen, Y. X., He, Y. F., Yang, Y., Yu, Y. L., Zheng, S. J., Tian, G. M., Luo, Y. M., and Wong, M. H. 2003. Effect of cadmium on nodulation and $\mathrm{N}_{2}$-fixation of soybean in contaminated soils. Chemosphere 50:781787.

Chong, J., Baltz, R., Schmitt, C., Beffa, R., Fritig, B., and Saindrenan, P. 2002. Downregulation of pathogen responsive tobacco UDPGlc:phenylpropanoid glucosyltransferase reduces scopoletic glucoside accumulation, enhances oxidative stress, and weakens virus resistance. Plant Cell. 14:1093-1107.

Day, D. A., Lambers, H., Bateman, J., Carroll, B. J., and Gresshoff, P. M. 1986. Growth comparisons of a supernodulating soybean (Glycine max) mutant and its wild-type parent. Physiol. Plant. 68:375-382.

Delves, A. C., Mathews, A., Day, D. A., Carter, A. S., Carroll, B. J., and 
Gresshoff, P. M. 1986. Regulation of the soybean-Rhizobium nodule symbiosis by shoot and root factors. Plant Physiol. 82:588-590.

Delves, A. C., Higgins, A., and Gresshoff, P. 1992. Shoot apex removal does not alter autoregulation of nodulation in soybean. Plant Cell Environ. 15:249-254.

Dong, X. 1998. SA, JA, ethylene, and disease resistance in plants. Curr. Opin. Plant Biol. 1:316-323.

Duc, G., and Messager, A. 1989. Mutagenesis of pea (Pisum sativum L.) and the isolation of mutants for nodulation and nitrogen fixation. Plant Sci. 60:207-213.

Ellard-Ivey, M., and Douglas, C. J. 1996. Role of jasmonates in the elicitor- and wound-inducible expression of defense genes in parsley and transgenic tobacco. Plant Physiol. 112:183-192.

Ferguson, B. J., Ross, J. J., and Reid, J. B. 2005. Nodulation phenotypes of gibberellin and brassinosteroid mutants of pea. Plant Physiol. 138:2396-2405

Feys, B., Benedetti, C. E., Penfold, C. N., and Turner, J. G. 1994. Arabidopsis mutants selected for resistance to the phytotoxin coronatine are male sterile, insensitive to methyl jasmonate, and resistant to a bacterial pathogen. Plant Cell. 6:751-759.

Fliegmann, J., Schuler, G., Boland, W., Ebel, J., and Mithofer, A. 2003. The role of octadecanoids and functional mimics in soybean defense responses. J. Biol. Chem. 384:437-446.

Gardner, H. W. 1991. Recent investigations into the lipoxygenase pathway of plants. Biochim. Biophys. Acta. 1084:221-239.

Graham, P. H., and Vance, C. P. 2003. Legumes: Importance and constraints to greater use. Plant Physiol. 131:872-877.

Gresshoff, P. M., and Delves, A. C. 1986. Plant genetic approaches to symbiotic nodulation and nitrogen fixation in legumes. Pages 159-206 in: Plant Gene Research III. A Genetical Approach to Plant Biochemistry. A. D. Blonstein and P. J. King, eds. Springer Verlag, Wien, Germany.

Halitschke, R., and Baldwin, I. T. 2003. Antisense LOX expression increases herbivore performance by decreasing defense responses and inhibiting growth-related transcriptional reorganization in Nicotiana attenuata. Plant J. 36:794-807.

Harms, K., Atzorn, R., Brash, A., Kuhn, H., Wasternack, C., Willmitzer, L., and Pena-Cortés, H. 1995. Expression of a flax allene oxide synthase cDNA leads to increased endogenous jasmonic acid (JA) levels in transgenic potato plants but not to a corresponding activation of JA-responding genes. Plant Cell. 7:1645-1654.

Hause, B., Maier, W., Miersch, O., Kramell, R., and Strack, D. 2002. Induction of jasmonate biosynthesis in arbuscular mycorrhizal barley roots. Plant Physiol. 130:1213-1220.

Hayashi, S., Gresshoff, P. M., and Kinkema, M. 2008. Molecular analysis of lipoxygenases associated with nodulation in soybean. Mol. Plant Microbe Interact. 21:843-853.

Isayenkov, S., Mrosk, C., Stenzel, I., Strack, D., and Hause, B. 2005. Suppression of allene oxide cyclase in hairy roots of Medicago truncatula reduces jasmonate levels and the degree of mycorrhization with Glomus intraradices. Plant Physiol. 139:1401-1410.

Jiang, Q., and Gresshoff, P. M. 2002. Shoot control of hypernodulation and aberrant root formation in the harl-1 mutant of Lotus japonicus. Funct. Plant Biol. 29:1371-1376.

Kinkema, M., Scott, P., and Gresshoff, P. M. 2006. Legume nodulation: Successful symbiosis through short and long-distance signalling. Funct. Plant Biol. 33:1-15.

Koch, T., Krumm, T., Jung, V., Engelberth, J., and Boland, W. 1999. Differential induction of plant volatile biosynthesis in the lima bean by early and late intermediates of the octadecanoid-signaling pathway. Plant Physiol. 121:153-162.

Kongrit, D., Jisaka, M., Iwanaga, C., Yokomichi, H., Katsube, T., Nishimura, K., Nagaya, T., and Yokota, K. 2007. Molecular cloning and functional expression of soybean allene oxide synthases. Biosci. Biotechnol. Biochem. 71:491-498.

Kosslak, R. M., and Bohlool, B. B. 1984. Suppression of nodule development of one side of a split-root system of soybeans caused by prior inoculation of the other side. Plant Physiol. 75:125-130.

Krusell, L., Madsen, L. H., Sato, S., Aubert, G., Genua, A., Szczyglowski, K., Duc, G., Kaneko, T., Tabata, S., de Bruijn, F., Pajuelo, E., Sandal, N., and Stougaard, J. 2002. Shoot control of root development and nodulation is mediated by a receptor-like kinase. Nature. 420:422426 .

Laudert, D., Schaller, F., Weiler, E. W. 2000. Transgenic Nicotiana tabacum and Arabidopsis thaliana plants overexpressing allene oxide synthase. Planta. 211:163-165.

Leibfried, A., To, J. P., Busch, W., Stehling, S., Kehle, A., Demar, M., Kieber, J. J., and Lohmann, J. U. 2005. WUSCHEL controls meristem function by direct regulation of cytokinin-inducible response regulators. Nature 438:1172-1175.

Li, C., and Wong, W. W. 2001. Model-based analysis of oligonucleotide arrays: Model validation, design issues and standard error application. Genome Biol. 2:1-11.

Liavonchanka, A., and Feussner, I. 2006. Lipoxygenases: Occurrence, functions and catalysis. J. Plant Physiol. 163:348-357.

Lohar, D. P., and Bird, D. M. 2003. Lotus japonicus: A new model to study root-parasitic nematodes. Plant Cell Physiol. 44:1176-1184.

Meixner, C., Ludwig-Müller, J., Miersch, O., Gresshoff, P., Staehelin, C. and Vierheilig, H. 2005. Lack of mycorrhizal autoregulation and phytohormonal changes in the supernodulating soybean mutant nts1007. Planta 222:709-715.

Nakagawa, T., and Kawaguchi, M. 2006. Shoot-applied MeJA suppresses root nodulation in Lotus japonicus. Plant Cell Physiol. 47:176-180.

Nishimura, R., Hayashi, M., Wu, G. J., Kouchi, H., Imaizumi-Anraku, H., Murakami, Y., Kawasaki, S., Akao, S., Ohmori, M., Nagasawa, M., Harada, K., and Kawaguchi, M. 2002. HAR1 mediates systemic regulation of symbiotic organ development. Nature 420:426-429.

Nishiuchi, T., Hamada, T., Kodama, H., and Iba, K. 1997. Wounding changes the spatial expression pattern of the arabidopsis plastid omega3 fatty acid desaturase gene (FAD7) through different signal transduction pathways. Plant Cell 9:1701-1712.

Nontachaiyapoom, S., Scott, P. T., Men, A. E., Kinkema, M., Schenk, P. M., and Gresshoff, P. M. 2007. Promoters of orthologous Glycine max and Lotus japonicus nodulation autoregulation genes interchangeably drive phloem-specific expression in transgenic plants. Mol. Plant Microbe Interact. 20:769-780.

Norton, G., Pappusamy, A., Yusof, F., Pujade-Renaud, V., Perkins, M., Griffiths, D., and Jones, H. 2007. Characterisation of recombinant Hevea brasiliensis allene oxide synthase: Effects of cycloxygenase inhibitors, lipoxygenase inhibitors, and salicylates on enzyme activity. Plant Physiol. Biochem. 45:129-138.

Oka-Kira, E., Tateno, K., Miura, K., Haga, T., Hayashi, M., Harada, K., Sato, S., Tabata, S., Shikazono, N., Tanaka, A., Watanabe, Y., Fukuhara, I., Nagata, T., and Kawaguchi, M. 2005. klavier (klv), a novel hypernodulation mutant of Lotus japonicus affected in vascular tissue organization and floral induction. Plant J. 44:505-515.

Olsson, J. E., Nakao, P., Bohlool, B. B., and Gresshoff, P. M. 1989. Lack of systemic suppression of nodulation in split root systems of supernodulating soybean (Glycine $\max$ [L.] Merr.) mutants. Plant Physiol. 90:1347-1352.

Paal, J., Henselewski, H., Muth, J., Meksem, K., Menendez, C. M., Salamini, F., Ballvora, A., and Gebhardt, C. 2004. Molecular cloning of the potato Gro1-4 gene conferring resistance to pathotype Ro1 of the root cyst nematode Globodera rostochiensis, based on a candidate gene approach. Plant J. 38:285-297.

Parish, D. J., and Leopold, A. C. 1978. Confounding of alternate respiration by lipoxygenase activity. Plant Physiol. 62:470-472.

Park, S. J., and Buttery, B. R. 1988. Nodulation mutants of white bean (Phaseolus vulgaris L.) induced by ethyl-methane sulfonate. Can. J. Plant Sci. 68:199-202.

Peña-Cortés, H., Albrecht, T., Prat, S., Weiler, E., and Willmitzer, L. 1993. Asprin prevents wound-induced gene expression in tomato leaves by blocking jasmonic acid biosynthesis. Planta 191:123-128.

Pierce, M., and Bauer, W. D. 1983. A rapid regulatory response governing nodulation in soybean. Plant Physiol. 73:286-290.

Ross, J., Li, Y., Lim, E., and Bowles, D. J. 2001. Higher plant glycosyltransferases. Genome Biol. 2: reviews3004.1-3004.6. Published online.

Royo, J., Vancanneyt, G., Perez, A. G., Sanz, C., Stormann, K., Rosahl, S., and Sanchez-Serrano, J. J. 1996. Characterization of three potato lipoxygenases with distinct enzymatic activities and different organspecific and wound-regulated expression patterns. J. Biol. Chem. 271:21012-21019.

Schilmiller, A. L., and Howe, G. A. 2005. Systemic signaling in the wound response. Curr. Opin. Plant Biol. 8:369-77.

Schnabel, E., Journet, E. P., de Carvalho-Niebel, F., Duc, G., and Frugoli, J. 2005. The Medicago truncatula SUNN gene encodes a CLV1-like leucine-rich repeat receptor kinase that regulates nodule number and root length. Plant Mol. Biol. 58:809-822.

Searle, I. R., Men, A. E., Laniya, T. S., Buzas, D. M., Iturbe-Ormaetxe, I., Carroll, B. J., and Gresshoff, P. M. 2003. Long-distance signaling in nodulation directed by a Clavata1-like receptor kinase. Science. 299:109112.

Seo, H. S., Li, J., Lee, S. Y., Yu, J. W., Kim, K. H., Lee, S. H., Lee, I. J., and Paek, N. C. 2007. The hypernodulating nts mutation induces jasmonate synthetic pathway in soybean leaves. Mol. Cells 24:185-193.

Shibata, D., Slusarenko, A., Casey, R., Hildebrand, D., and Bell, E. 1994. Lipoxygenases. Plant Mol. Biol. Rep. 12:S41-42.

Shrihari, P. C., Sakamoto, K., Inubushi, K., and Akao, S. 2000. Interaction between supernodulating or non-nodulating mutants of soybean and two arbuscular mycorrhizal fungi. Mycorrhiza 10:101-106.

Solaiman, M. Z., Senoo, K., Kawaguchi, M., Imaizumi-Anraku, H., Akao, 
S., Tanaka, A., and Obata, H. 2000. Characterization of mycorrhizas formed by Glomus sp. on roots of hypernodulating mutants of Lotus japonicus. J. Plant Res. 113:443-448.

Stacey, G., Libault, M., Brechenmacher, L., Wan, J., and May, G. D. 2006. Genetics and Functional genomics of legume nodulation. Curr. Opin. Plant Biol. 9:110-121.

Staswick, P. E., Huang, J. F., and Rhee, Y. 1991. Nitrogen and methyl jasmonate induction of soybean vegetative storage protein genes. Plant Physiol. 96:130-136.

Staswick, P. E., Su, W., and Howell, S. H. 1992. Methyl jasmonate inhibition of root growth and induction of a leaf protein are decreased in an Arabidopsis thaliana mutant. Proc. Natl. Acad. Sci. U.S.A. 89:6837-6840.

Stumpe, M., Carsjens, J. G., Stenzel, I., Göbel, C., Lang, I., Pawlowski, K., Hause, B., and Feussner, I. 2005. Lipid metabolism in arbuscular mycorrhizal roots of Medicago truncatula. Phytochemistry 66:781-791.

Szczyglowski, K., Shaw, R.S., Wopereis, J., Copeland, S., Hamburger, D. Kasiborski, B., Dazzo, F. B., and de Bruijn, F. J. 1998. Nodule organogenesis and symbiotic mutants of the model legume Lotus japonicus. Mol. Plant Microbe Interact. 11:684-697.

Taki, N., Sasaki-Sekimoto, Y., Obayashi, T., Kikuta, A., Kobayashi, K., Ainai, T., Yagi, K., Sakurai, N., Suzuki, H., Masuda, T., Takamiya, K., Shibata, D., Kobayashi, Y., and Ohta, H. 2005. 12-oxo-phytodienoic acid triggers expression of a distinct set of genes and plays a role in wound-induced gene expression in Arabidopsis. Plant Physiol. 139:1268-1283.

Tazawa, J., Takahashi, M., Usuki, K., and Yamamoto, H. 2007. Nodulation during vegetative growth of soybean stage does not affect the susceptibility to red crown rot caused by Calonectria ilicicola. J. Gen. Plant Pathol. 73:180-184.

Terakado, J., Fujihara, S., Goto, S., Kuratani, R., Suzuki, Y., Yoshida, S., and Yoneyama, T. 2005. Systemic effect of a brassinosteroid on root nodule formation in soybean as revealed by the application of brassinolide and brassinazaole. Soil Sci. Plant Nutr. 51:389-395.

Truman, W., Bennett, M. H., Kubigsteltig, I., Turnbull, C., and Grant, M. 2007. Arabidopsis systemic immunity uses conserved defense signaling pathways and is mediated by jasmonates. Proc. Natl. Acad. Sci. U.S.A. 104:1075-1080
Vance, C. P. 1983. Rhizobium infection and nodulation: A beneficial plant disease? Annu. Rev. Microbiol. 37:399-424.

van Noorden, G. E., Ross, J. J., Reid, J. B., Rolfe, B. G., and Mathesius,

U. 2006. Defective long-distance auxin transport regulation in the Medicago truncatula super numeric nodules mutant. Plant Physiol. 140:1494-1506.

van Noorden, G. E., Kerim, T., Goffard, N., Wiblin, R., Pellerone, F. I., Rolfe, B. G., and Mathesius, U. 2007. Overlap of proteome changes in Medicago truncatula in response to auxin and Sinorhizobium meliloti. Plant Physiol. 144:1115-1131.

Velagaleti, R. R., and Marsh, S. 1989. Influence of host cultivars and Bradyrhizobium strains on growth and symbiotic performance of soybean under salt stress. Plant Soil 119:133-138.

Wasternack, C., Stenzel, I., Hause, B., Hause, G., Kutter, C., Maucher, H., Neumerkel, J., Feussner, I., and Miersch, O. 2006. The wound response in tomato-role of jasmonic acid. J. Plant Physiol. 163:297-306.

Woo, H. H., Faull, K. F., Hirsch, A. M., and Hawes, M. C. 2003. Altered life cycle in Arabidopsis plants expressing PsUGT1, a UDP-glucuronosyltransferase-encoding gene from pea. Plant Physiol. 133:538-548.

Wopereis, J., Pajuelo, E., Dazzo, F. B., Jiang, Q., Gresshoff, P. M., de Bruijn, F.J., Stougaard, J., and Szczyglowski, K. 2000. Short root mutant of Lotus japonicus with a dramatically altered symbiotic phenotype. Plant J. 23:97-114.

Yamamoto, E., Caglar, H., and Knap, H. T. 2000. Molecular characterization of two soybean homologs of Arabidopsis thaliana CLAVATA1 from the wild type and fasciation mutant. Biochim. Biophys. Acta. 1491:333340 .

Zablotowicz, R. M., and Reddy, K. N. 2004. Impact of glyphosate on the Bradyrhizobium japonicum symbiosis with glyphosate-resistant transgenic soybean: A minireview. J. Environ. Qual. 33:825-831.

\section{AUTHOR-RECOMMENDED INTERNET RESOURCES}

Cheng Li Lab dCHIP software webpage: www.dchip.org

NCBI BLAST homepage: www.ncbi.nlm.nih.gov/BLAST

TIGR gene indices website: compbio.dfci.harvard.edu/tgi/plant.html 